\title{
Active and reactive power regulation in doubly fed asynchronous generator
}

\author{
Cezary Jędryczka ${ }^{1, *}$, Jacek Prościak ${ }^{1}$ \\ ${ }^{1}$ Poznan University of Technology, Institute of Electrical Engineering and Electronics, ul. Piotrowo 3a, 60—965 Poznan, Poland
}

\begin{abstract}
The paper deals with active and reactive power regulation in doubly fed induction generator (DFIG) installed in the wind energy conversion system (WECS). The mathematical model of the studied machine has been proposed and suited for implementation of the field oriented control algorithm (FOC). The control strategy for decoupling the active and reactive power regulation has been proposed and implemented in Matlab/Simulink environment. Selected results of simulations have been presented and discussed.
\end{abstract}

\section{Introduction}

Increasing global energy consumption and conscious about environmental impact and the depleting reservoirs of fossil fuels are the driving force of progress in exploitation of renewable power resources. The number installed and operated WECS is continuously rising. Nevertheless the exploitation of the wind power is connected with problems of the power system stability and energy quality $[1,2]$. As the percentage of WECS power starts to be remarkable against other sources in the power systems the methods of controlling of active and reactive power generated by WECS are imminent need [2].

Due to the improved power quality, lower cost of power electronic converter, high energy efficiency and controllability the variable speed wind turbines with DFIG are consequently used as an alternative to the direct drive turbines using permanent magnet synchronous generators (PMSG). The WECS with DFIG has been schematically illustrated in Fig. 1.

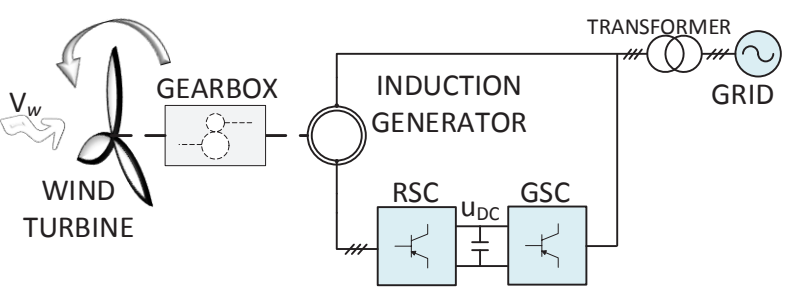

Fig. 1. Scheme of the DFIG operated WECS.

As stated above one of the crucial advantages of using DFIG in WECS is controllability. By changing frequency of currents in the rotor windings such system can operate in wide range of the turbine speed. Taking into account that most of the high power wind turbines are equipped with blade pitch control system the application of DFIG allows to optimize the system efficiency in wide range of the wind speeds using complex maximum power point tracking (MPPT) algorithms [3]. Moreover, in contrast to PMSG operated WECS the power controllability is achieved by power electronic converters of fairly low power rating about 20 to $30 \%$ of total machine power.

\section{Model of DFIG operated WECS}

There are number of approaches of different computational complexity and accuracy which have been utilized for modeling of DFIG operated WECS [1-5]. Most of them concern electromagnetic models including power electronics converters which are suitable for the detailed study of the power conversion system and its control strategies.

This paper proposes a simplified model of DFIG operated WECS including the wind turbine model, mechanical equilibrium equation, electromagnetic model of the DFIG and power control system. The grid and rotor power electronic converters (GSC and RSC in Fig. 1, respectively) are simulated in simplified manner i.e. as a ideal voltage source controlling the rotor current and frequency according to known orientation of the stator flux. The developed model of the machine and control system of DFIG operated WECS has been schematically illustrated in Fig. 2. Detailed description of the developed model has been discussed in [4].

\section{Active and reactive power control}

Elaborated model has been supplemented by the control system consisting of Power and Current controllers, respectively.

Corresponding author: cezary.jedryczka@put.poznan.pl 


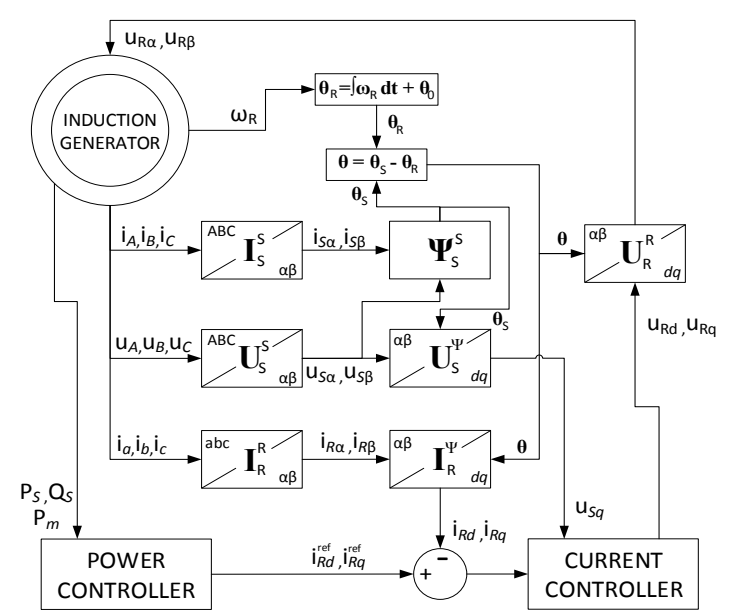

Fig. 2. Scheme of the developed model and control system.

The diagram of Power controller and Current controller has been shown in Fig. 3a, 3b and 3c, respectively.

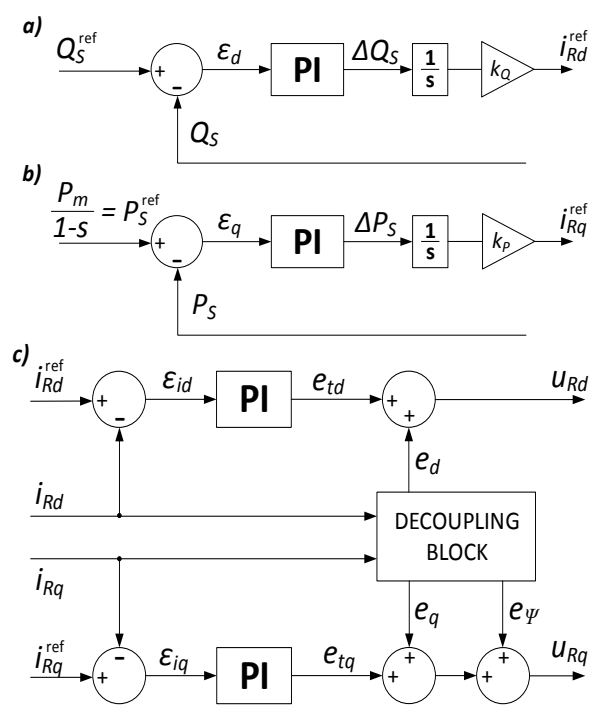

Fig. 3. Block diagrams of Power controller $(a, b)$ and Current controller (c).

The current controller consists of decoupling block allowing for independent control of direct and quadrature currents $[4,5]$. The active power controller has been tested for operation of WECS at different wind speeds assuming constant blade pitch angle of the turbine. The reference and response signal of the active power at forced wind speed waveform (green curve) has been shown in Fig 4.

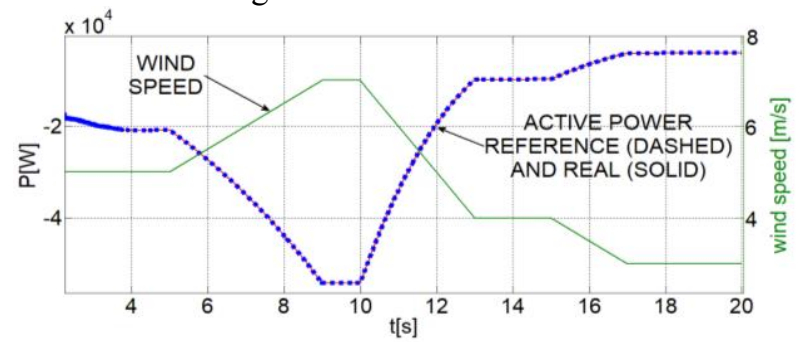

Fig. 4. Simulation results for active power controller.
The reactive power controller has been validated for the test reference signal shown in Fig 5. Additionally rotor power and rotor currents have been presented in Fig. 6. to illustrate response of machine for power control at transition from sub- to super-synchronous speed.

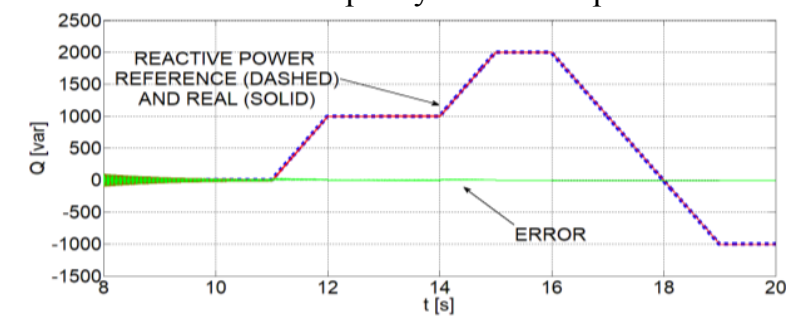

Fig. 5. Simulation results for reactive power controller.
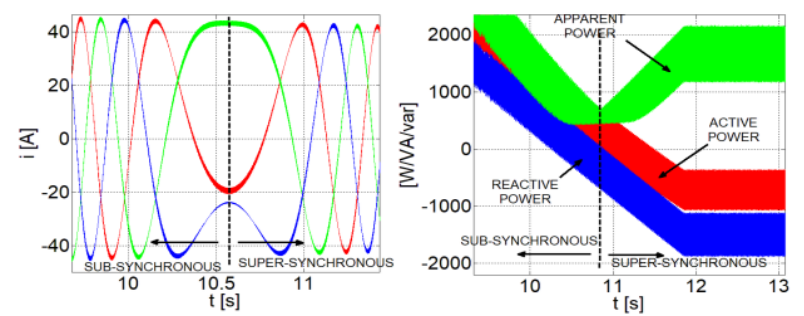

Fig. 6. Simulation results for sub- to super-synchronous operation moment - rotor currents (left), rotor power (right).

\section{Conclusions}

This paper discuss a simplified model of DFIG operated WECS including the wind turbine model, mechanical equilibrium equation, electromagnetic model of the DFIG and power control system.

Active power of the DFIG system depends on machine torque and rotor speed, whereas reactive power of the DFIG can be in independently controlled by core magnetization. Comprehensive power control is achieved by controlling machine electromagnetic torque and machine flux by rotor current space vector in quadrature axis and direct axis respectively, in reference to the stator flux. The DFIG can operate in both, suband super-synchronous modes. During transition between those modes the change of energy flow direction through rotor windings and reverse rotor currents phase shifting can be observed.

The capability of DFIG system to produce controllable active and reactive power is beneficial in terms of optimal wind energy conversion and power grid supporting during the disturbances.

\section{References}

1. Y. Lei, A. Mullane, G. Lightbody, R. Yacamini, IEEE Trans. on Energy Conversion 21, 257-264 (2006)

2. H. Xu, X. Ma, D. Sun, Jour. of Power El. 15, 235 $245(2015)$

3. L. Sun, Z. Mi, Y. Yu, T. Wu, H. Tian, SUPERGEN '09,1-6 (2009)

4. C. Jędryczka, J. Prościak, Pozn. Univ. Technol. Acad. J. Electr. Eng. 94, 26 (2018)

5. HC. Chen, PH. Chen, Appl. Math. Inf. Sci. 8, $117-$ 124 (2014)

Corresponding author: cezary.jedryczka@put.poznan.pl 